\title{
遷移金属触媒を用いないヘテロ芳香族化合物のクロスカップリング反応の開発
}

\author{
森本 功治
}

\section{Metal-free Direct Biaryl Coupling Reaction of Heteroaromatic Compounds via Iodonium Intermediate}

\author{
Koji MoRimoto \\ College of Pharmaceutical Sciences, Ritsumeikan University, \\ 1-1-1 Nojihigashi, Kusatsu, Shiga 525-0058, Japan
}

(Received May 30, 2011)

\begin{abstract}
Biaryl compounds are versatile building blocks in the synthesis of natural products, pharmaceuticals, agricultural chemicals and $\pi$-conjugated organic materials. This review describes a recent progress for the biaryl cross-coupling reaction of heteroaromatic compounds using hypervalent iodine reagent. Our novel biaryl coupling reaction is a unique method for constructing various heteroaromatic biaryls without use of transition metal catalysts. From mechanistic point of view, the coupling reaction was realized through stable iodine intermediate generated from heteroaroamatic compound and iodine (III) reagent.
\end{abstract}

Key words - hypervalent iodine; biaryl; heteroaromatic compound; iodonium intermediate

\section{1.はじめに}

有機化合物中の 2 つの性質の異なる炭素と炭素 を，触媒を用いて結合させるクロスカップリング反 応は，日本で生まれた化学分野の革新技術として世 界からも高く評価され，その応用は多岐にわたって いる．現在最も汎用されている芳香環に芳香環をつ なぐクロスカップリング反応は，レアメタルである パラジウムを用いた根岸カップリングや鈴木カップ リングに代表される手法であるが，さらに新しいク ロスカップリング反応を求めて, 活発な研究開発が 行われている.1 現在頻用されている手法は，触媒 としてレアメタルを用い，芳香環にハロゲンやメタ ルを導入して官能基化を行う必要があり，そのため に反応工程が長くなることが課題である。一方，こ のような官能基化を必要としない手法として，酸化 的手法を用いたクロスカップリング反応が検討され るようになってきた. ${ }^{2-4)}$ 酸化的カップリング反応 は，芳香環にハロゲン化やメタル化等の官能基化が

立命館大学薬学部（干525-0058 滋賀県草津市野路東 1 $-1-1)$

e-mail: k-morimo@fc.ritsumei.ac.jp

本総説は, 平成 22 年度日本薬学会近畿支部奨励賞（化 学系薬学）の受賞を記念して記述したものである.
あらかじめ必要な結合形成反応に比べ，原料の構造 修飾を必要としない直接的かつ簡便で副産物の少な い有用な手法である（Scheme 1)。しかし，酸化的 手法を用いたクロスカップリング反応の場合，目的 とするカップリング体のほかに，ホモダイマーが副 生するといつた問題があり, 反応の制御が困難で, 効果的な手法は最近まで報告されていなかった.

一方筆者らは，超原子価ヨウ素反応剤を用いる， 新しい芳香族化合物類の酸化的クロスカップリング 反応の開発に成功し，その有用性を明らかにしてき た．本総説では本反応の詳細について述べる.

2. 超原子価ヨウ素反応剤を用いた酸化的カップ リングの開発

先にも述べたように, 酸化的クロスカップリング 反応は，非常に短工程で生成物が得られる理想的な 方法である。しかし，これまでの技術では，例えば 芳香環 A と芳香環 B をカップリングさせる場合, 目的のクロスカップリング体 A-B のみではなく $\mathrm{A}-$ A あるいは B-B といったホモカップリング体が副 生するという問題があった. したがって酸化的カッ プリング反応においてホモカップリング体を副生す ることなく，クロスカップリング体を選択的に得る ことが重要な課題である. 


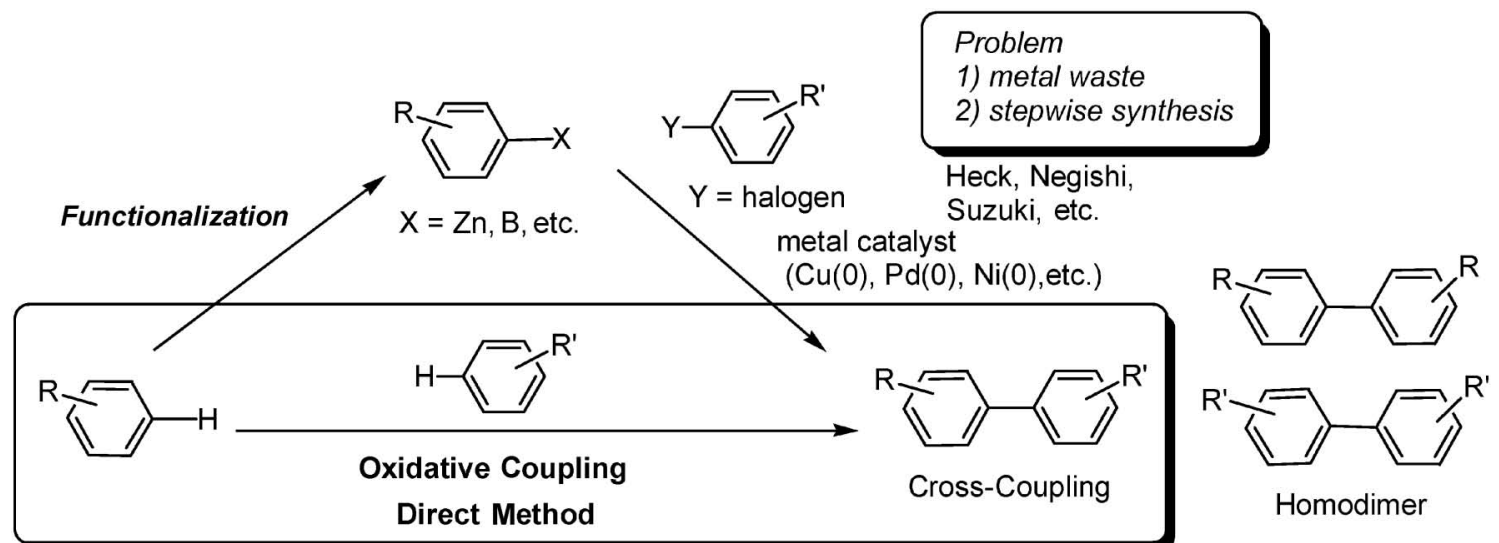

Scheme 1. Typical Biaryl Coupling Reaction of Aromatic Compounds

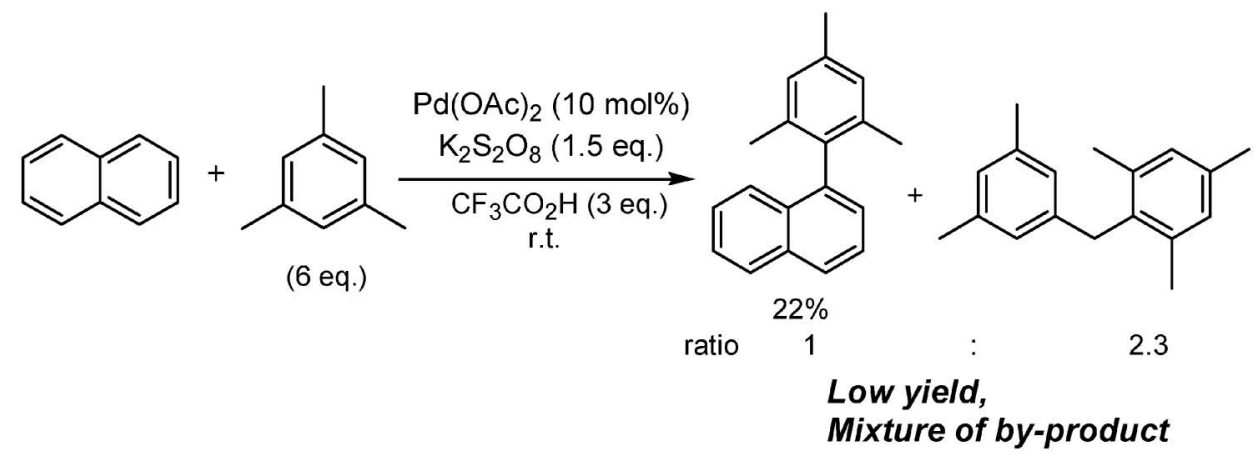

Scheme 2. Palladium Catalyzed Oxidative Coupling Reaction of Aromatic Compound

一方でヨウ素は，日本が産出量第 2 位を誇る固有 資源である，われわれの研究室では，これまでに毒 性の強い重金属酸化剂の代替としての超原子価ヨウ 素反応剂 phenyliodine bis (trifluoroacetate) (PIFA) と，電子豊富な芳香族化合物を極性が高く求核性の 低い多フッ化アルコール中で反応させると，カチオ ンラジカル種を生成することを発見し, 芳香環に一 挙に求核種を導入することに成功した. 本手法を複 雑な構造を有する天然物の全合成や，へテロ芳香族 化合物の結合形成反応に応用し，その有用性を明ら かにしてきた. ${ }^{5,6)}$ しかしながら, 炭素求核種導入反 応においては分子内反応以外では，芳香族化合物の クロスカップリング反応に成功していなかつ た. ${ }^{7-12)}$ 最近になってパラジウム触媒を用いるナフ タレンとメシチレンの酸化的カップリングが報告さ れたが, 反応活性の高いメシチレンの二量化体が主 生成体で, 目的のクロスカップリング体はわずか 22\%しか得られていなかった (Scheme 2).13)

このような背景下, 筆者は超原子価ヨウ素反応剂

を用いる芳香族化合物のクロスカップリング反応の 開発研究に着手した。種々検討した結果，低温下， ヨウ素反応剤 PIFA と多フッ化アルコールの代わり に $\mathrm{BF}_{3} \cdot \mathrm{Et}_{2} \mathrm{O}$ を存在させると, 先と同様の基質であ るナフタレンとメシチレンにおいて, クロスカップ リング体が選択的に得られることがわかつた (Scheme 3). ${ }^{14)}$

基質一般性については, Fig. 1 に示した。図には 種々芳香族化合物のカップリングにより得られるク ロスカップリング体を示している. ナフタレン類や フェナントレンを基質として用いても収率よく目的 物が得られた。 また，ハロゲンを置換基として有す

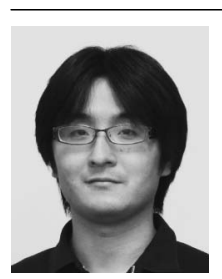

森本功治
立命館大学グローバル・イノベーショ ン研究機構ポストドクトラルフェ ロー。博士 (薬学). 奈良県出身. 2004 年大阪大学薬学部総合薬学科卒業, 2006 年同大学院薬学研究科博士前期課 程修了, 2009 年大阪大学大学院薬学研 究科博士後期課程修了。2009 年 4 月よ り現職。 


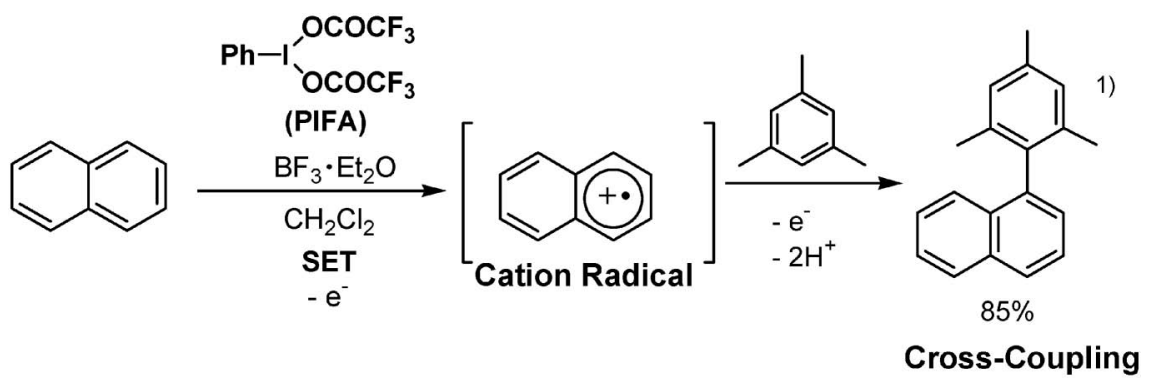

Scheme 3. Oxidative Coupling Reaction of Aromatic Compound Using Hypervalent Iodine Reagent<smiles>[R]c1ccc(-c2c(C)cc(C)cc2C)c2ccccc12</smiles>

$\mathrm{R}=\mathrm{H} ; 63 \%$

$\mathrm{Ph} ; 56 \%$<smiles>[R]c1cc2ccc(Br)cc2c(-c2c(C)cc(C)cc2C)c1[R]</smiles>

$\mathrm{R}^{1}=\mathrm{Me}, \mathrm{R}^{2}=\mathrm{H} ; 82 \%$

$R^{1}=H, R^{2}=M e ; 57 \%$<smiles>Cc1cc(C)c(-c2cc3ccccc3c3ccccc23)c(C)c1</smiles>

$78 \%$<smiles>COc1ccc(-c2c(C)cc(C)cc2C)cc1I</smiles>

$60 \%$<smiles>[R]c1cc([R])c(-c2cccc3ccc(Br)cc23)c([R])c1</smiles>

$\mathrm{R}=$ Ethyl; $87 \%$

$=i-\operatorname{Pr} ; 70 \%$

Fig. 1. Generality<smiles></smiles><smiles>[R]c1ccccc1O[Na]</smiles>

(30-60 eq.)

$\mathrm{Pd}(\mathrm{TFA})_{2}(5 \mathrm{~mol} \%)$ excess of starting material

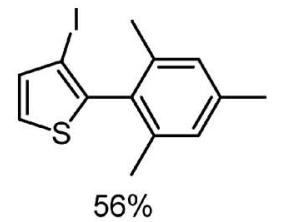

$\operatorname{AgOAc}(3$ eq.)

PivOH (6 eq.)

$110^{\circ} \mathrm{C}$<smiles>[R]c1ccc(-c2cn([R1])c3ccccc23)cc1</smiles>

$53-90 \%$

Scheme 4. Palladium Catalyzed Oxidative Coupling Reaction of Herteroaromatic Compounds

る基質においても反応中にハロゲン部位が損なわれ ることなく反応が進行する．この残存するハロゲン を利用して更なる化学変換が可能であり，われわれ のカップリング反応の非常に興味深い特徵である.

\section{3. ヘテロ芳香族化合物の酸化的カップリング}

本クロスカップリング反応の拡張として, 生物活 性天然物や導電性ポリマー等の重要な骨格の 1 つで あるビスへテロ芳香族化合物に注目した．インドー ル類やピロール類等のヘテロ芳香族化合物の酸化的
カップリングは, 酸化電位の低さから非常に困難で ある. 最近, 不安定なへテロ芳香環の酸化的クロス カップリング反応が達成されたが，過剰な基質の使 用と高温を必要とし，さらに酸化剂のほかにレアメ タルの添加が必要で，収率にも問題が残っていた (Scheme 4).15)

$$
\text { チオフェン } \mathbf{1} \text { とナフタレン } 2 \text { を基質として用い, }
$$
先のアルキルアレーン類のクロスカップリング反応 で見い出した低温下，塩化メチレン中，ルイス酸と 


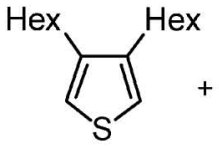

1<smiles>COc1cccc2ccccc12</smiles>

2

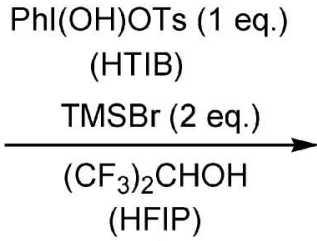

r.t.<smiles>COc1ccc(-c2scc(C(=O)O)c2[GeH2])c2ccccc12</smiles>

3

$86 \%$
No homodimers
して $\mathrm{BF}_{3} \cdot \mathrm{Et}_{2} \mathrm{O}$ や TMSOTf を用いる条件では反応 は全く進行しなかった。しかしながら種々条件を検 討した結果, ヨウ素反応剂として [hydroxy (tosyloxy) iodo] benzene ( $\mathrm{PhI}(\mathrm{OH})$ OTs, HTIB) と bromo (trimethyl) silane（TMSBr）を用い，さらに溶媒と して高極性な $\left(\mathrm{CF}_{3}\right)_{2} \mathrm{CHOH}$ (HFIP) を用いたと ころ, 原料は完全に消失し, クロスカップリング体 3 が高収率で得られることがわかった [Eq. (1)].

さらに，本反応の反応機構を明らかにするため実 験を行ったところ，ヨードニウム中間体を経由す る，新規な反応機構で進行していることを明らかに した（Scheme 5)。すなわち，本反応において，チ オフェン 1 を HFIP 中で TMSBr を添加せずに HTIB と反応させると, チオフェンのジアリール ヨードニウム塩 4-OTs が収率よく得られた. ${ }^{16-18)}$ そ こで，本反応でこのヨードニウム塩が反応中間体で はないかと考え，得られた 4-OTsに TMSBr を添加 せず，ナフタレン 2 を加えて攪拌したが，目的のカ ップリング体 3 は全く得られず，4-OTs が回収され
るのみであった。一方で， $\mathrm{TMSBr}$ を添加し反応を 行ったところ，カップリング体 $\mathbf{3}$ が良好な収率で得 られた。 また TMSBr の役割の 1 つとして，ヨード ニウムトシラート4-OTs のリガンド交換を起こ し，より反応性の高いヨードニウムブロミド（A） を中間体として生成することを明らかにした。

以上の知見から，チオフェン類を始めとするへテ 口芳香族化合物を, HFIP 中, TMSBr 存在下, ヨ ウ素反応剤 HTIB と反応させてヨードニウムブロ ミド 4-Br を生成後にカップリング相手と反応させ ることで，クロスカップリング反応を用いた様々な ヘテロ芳香族ビアリール化合物の合成法とした (Scheme 6)。本法では，へテロ芳香環一炭素芳香環 だけでなく，性質の類似しているへテロ芳香環同士 の選択的なクロスカップリングが可能である. ${ }^{19,20)}$

\section{3 位置換チオフェン類の位置選択的酸化的力} ップリング

次に筆者はへテロ芳香族ビアリール類の中で, head-to-tail（H-T）型のビチオフェンに興味をもつ

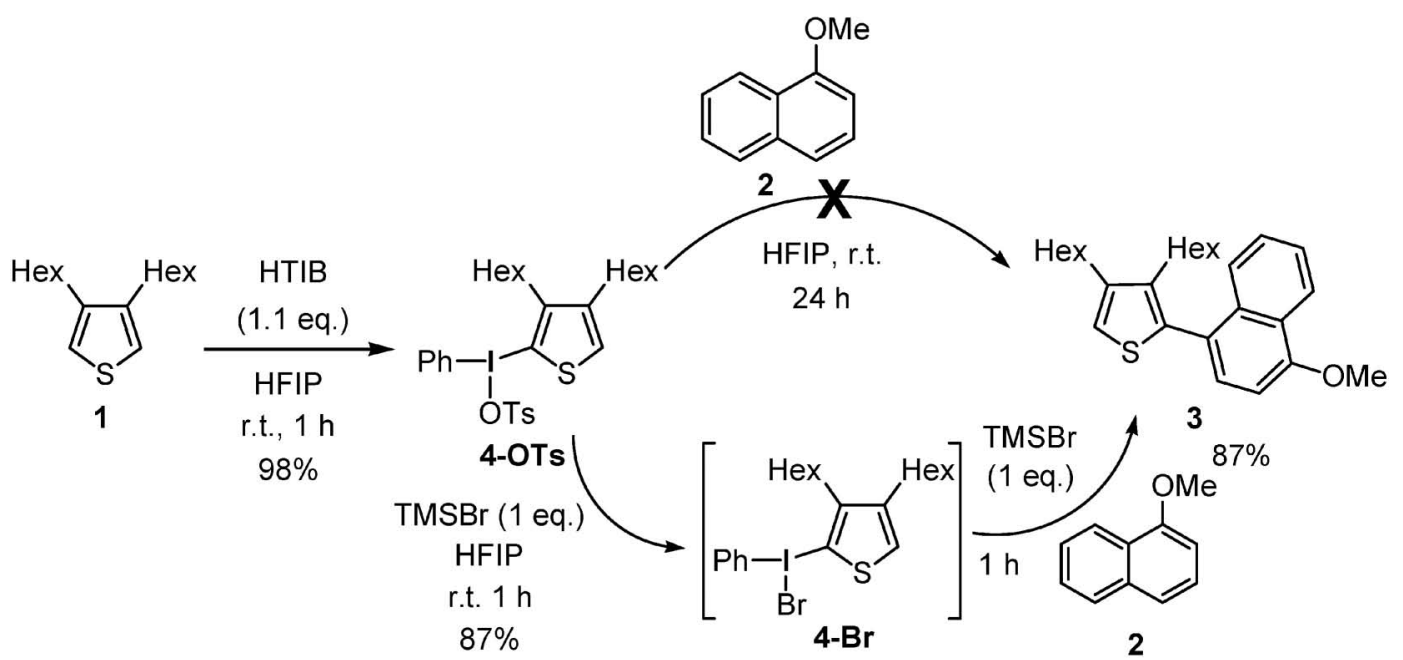

Scheme 5. Reactivity of Iodonium Salt 


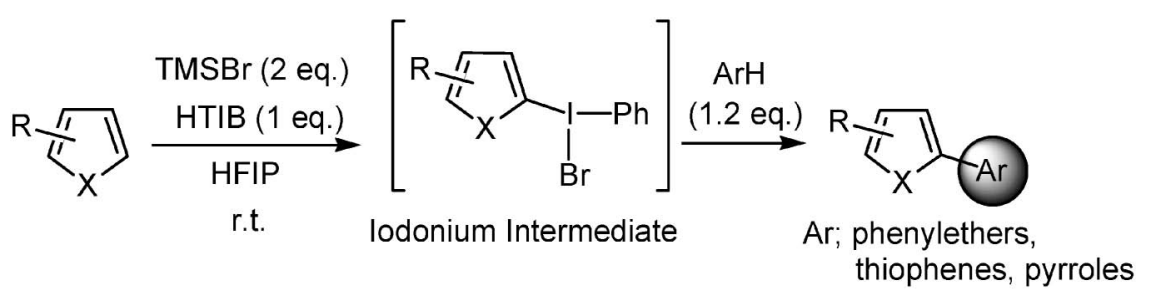<smiles>COc1ccc(-c2scc([GaH2])c2[18OH])c2ccccc12</smiles>

$86 \%$<smiles>COc1ccc(-c2cc(C)c(C)s2)c(OC)c1</smiles><smiles>c1ccc(-c2cscc2-c2scc3c2OCCO3)cc1</smiles>

$78 \%$<smiles>[H][R4](=O)c1ccsc1-c1cc([GeH])cs1</smiles>

$60 \%$<smiles>Cc1cc(-c2cccn2C(O)(Br)OCc2ccccc2)sc1C</smiles>

Scheme 6. Cross-coupling Reaction of Heteroaromatic Compound

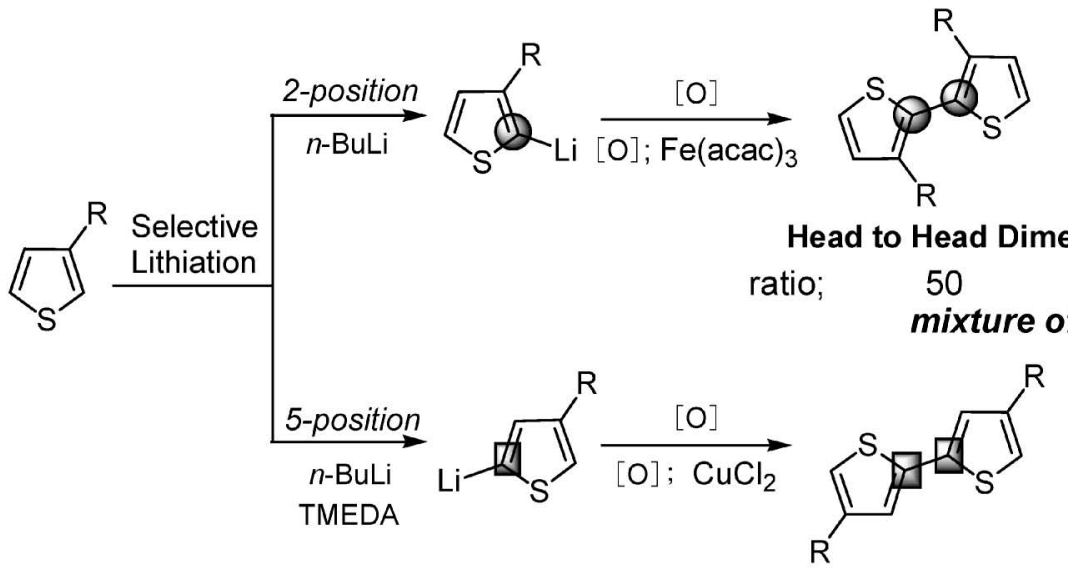

Tail to Tail Dimer

Scheme 7. General Methods for Oxidative Coupling Reaction of 3-Substituted Thiophenes

たＨ-T 型のビチオフェンは，高導電性を示すポ リチオフェンの有用な合成前駆体として重要な化合 物であるが, ${ }^{21,22)} 3$ 位置換チオフェン類の酸化的力 ップリング反応では，対称な head-to-head (H-H) 体, tail-to-tail（T-T） 体のみの合成しか報告され ていなかった (Scheme 7).23-25) これに対して, チ オフェン類の直接的な位置選択的カップリングはこ れまで一例も報告されていなかった.

そこで, 先のチオフェンのヨードニウム塩の反応 性に注目し，3 位置換チオフェン類 $\mathbf{5}$ に適用すれ ば，位置選択的なカップリング反応が可能になるの
ではないかと考えた。まず，種々の 3 位置換チオフ エンを HFIP 中, ヨウ素反応剤 HTIB と反応さ せ，続いて TMSBr を 1 等量加えることで， 2 位で 反応したヨードニウムブロミド 6-Br を収率よく合 成した。続いて，このヨードニウムブロミド 6-Br に対し，さらに TMSBr とチオフェン 5 を 1 等量加 えると, チオフェンの 2 位が選択的にヨードニウム 塩の 5 位と反応し, H-T 体 7 (H-T) のみが選択的 に得られることがわかつた (Scheme 8). ${ }^{26)}$ 基質汎 用性に関しては詳細は省略するが，電子豊富アルコ キシ基やアルキル基をもつ様々なチオフェン類が適 


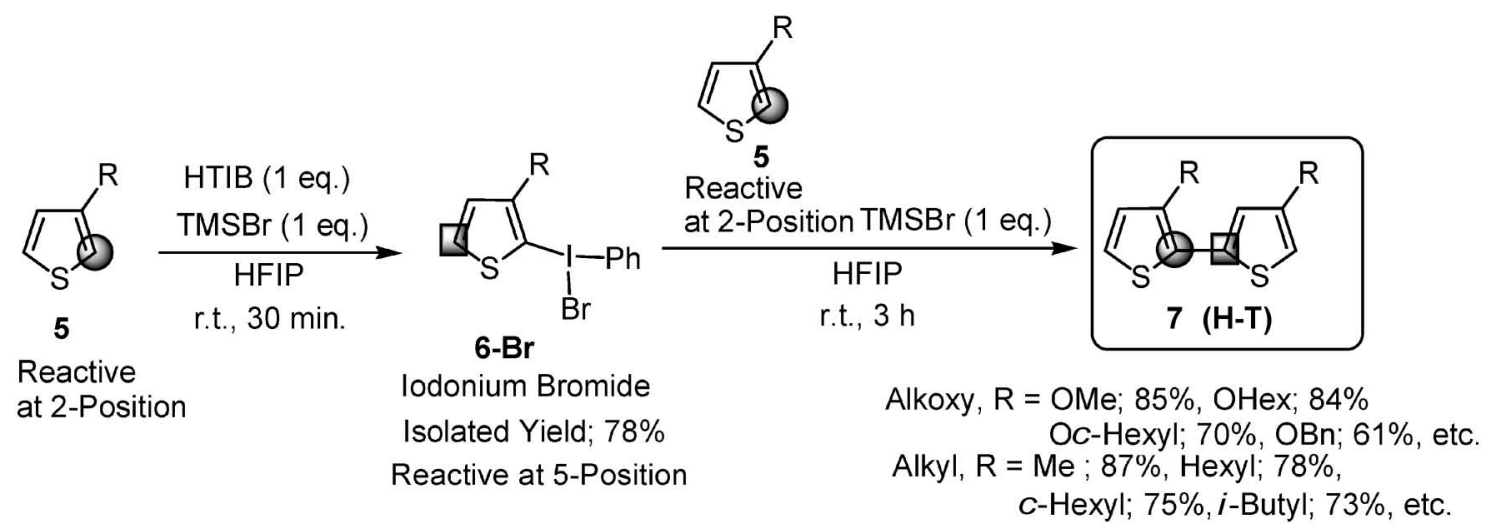

Scheme 8. Regioselective Coupling Reaction of 3-Substituted Thiophene

用可能である.

\section{5. おわりに}

以上，筆者は遷移金属を用いない一般性の高い新 規へテロ芳香族ビアリール類の合成法の開発に成功 し, さらに本反応がヨードニウム中間体を経由して 進行するユニークな反応機構で進行していることを 明らかにした。本手法は，直接的かつ位置選択的に 電子豊富なへテロ芳香族化合物に炭素-炭素結合を 形成できる有用な手法として，現在汎用されている 遷移金属触媒を用いた方法にとって代わるものとし て大いに期待できる。 さらに現在，開発した反応に より合成できる特定のへテロ芳香族クロスカップリ ング体を酸化重合させて得られるポリマーが，溶剤 分散性を有するだけでなく，高い導電性や透明性並 びに，優れた耐酸化性を有することがわかってい

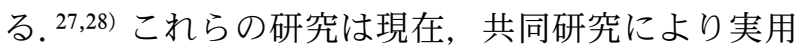
化を目指している.

\section{謝辞本研究を行うのに際し, 終始ご指導頂き} ました立命館大学薬学部教授（大阪大学名誉教授） 北 泰行先生に感謝致します。また，本研究に御協 力頂きました共同研究者の学生の方々に感謝致しま す。最後に，本研究を行うに当たり支援頂きました 日本学術振興会に感謝致します。

\section{REFERENCES}

1) Jana C., Pathak T. P., Sigman M. S., Chem. Rev., 111, 1417-1492 (2011).

2) McGlacken G. P., Bateman, L. M., Chem. Soc. Rev., 38, 2447-2464 (2009).

3) Ashenhurst A. J., Chem. Rev. Soc., 39, 540-
548 (2010).

4) Yeung C. S., Dong V. M., Chem. Rev., 111, 1215-1292 (2011).

5) Kita Y., Tohma H., Hatanaka K., Takada T., Fujita S., Mitoh S., Sakurai H., Oka S., J. Am. Chem. Soc., 116, 3684-3691 (1994).

6) Tohma H., Kita Y., Top. Curr. Chem., 224, 209-248 (2003).

7) Tohma H., Morioka H., Takizawa S., Arisawa M., Kita Y., Tetrahedron, 57, 345-352 (2001).

8) Tohma H., Iwata M., Maegawa T., Kita Y., Tetrahedron Lett., 8, 5377-5380 (2002).

9) Dohi T., Morimoto K., Kiyono Y., Maruyama A., Tohma H., Kita Y., Chem. Commun., 2930-2931 (2005).

10) Dohi T., Morimoto K., Maruyama A., Kita Y., Org. Lett., 8, 2007-2010 (2006).

11) Dohi T., Morimoto K., Ito M., Kita Y., Synthesis, 2913-2919 (2007).

12) Dohi T., Morimoto K., Takenaga N., Goto A., Maruyama A., Kiyono Y., Tohma H., Kita Y., J. Org. Chem., 72, 109-116 (2007).

13) Li R., Lu W., Organometallics, 26, 4376-4378 (2007).

14) Dohi T., Ito M., Morimoto K., Iwata M., Kita Y., Angew. Chem. Int. Ed. Engl., 47, 13011304 (2008).

15) Stuart D. R., Fagnou K., Science, 316, 11721175 (2007).

16) Dohi T., Ito M., Morimoto K., Minamitsuji Y., Takenaga N., Kita Y., Chem. Commun., 4152-4154 (2007).

17) Dohi T., Ito M., Yamaoka N., Morimoto K., Fujioka H., Kita Y., Tetrahedron, 65, 10797- 
10815 (2009).

18) Dohi T., Yamaoka N., Kita Y., Tetrahedron, 66, 5775-5785 (2010).

19) Kita Y., Morimoto K., Ito M., Ogawa C., Goto A., Dohi T., J. Am. Chem. Soc., 131, 1668-1669 (2009).

20) Dohi T., Ito M., Yamaoka N., Morimoto K., Fujioka H., Kita Y., Angew. Chem. Int. Ed. Engl., 49, 3334-3337 (2010).

21) Tonzola J. C., Alam M. M., Bean A. B., Jenekhe A. S., Macromolecules, 37, 3554 (2004).

22) Osaka I., Mccullough D. R., Acc. Chem. Res., 41, 1202-1214 (2008).

23) Marsella M. J., Carroll P. J., Swager T. M., J.
Am. Chem. Soc., 116, 9347-9348 (1994).

24) Allared F., Hellberg J., Remonen T., Tetrahedron Lett., 43, 1553-1554 (2002).

25) Barbosa F., Eberson L., Gesheidt G., Gronowitz S., Hornfeldt A.-B., Persson O., Acta Chem. Scand., 52, 1275-1284 (1998).

26) Morimoto K., Yamaoka N., Ogawa C., Nakae T., Fujioka, H., Dohi T., Kita Y., Org. Lett., 12, 3804-3807 (2010).

27) Chigusa Y., Morimoto K., Kita Y., Jpn. Kokai Tokkyo Koho JP 2009-46653A.

28) Kita Y., Dohi T., Morimoto K., Morita Y., Hosomi T., Ishioka S., PCT Int. Appl. WO 2010007648 (2010). 